\title{
Temperature effects on the hydraulic behaviour of an unsaturated clay
}

\author{
E. ROMERO, ${ }^{\star}$ A. GENS and A. LLORET \\ Geotechnical Engineering Laboratory, Department of Geotechnical Engineering and \\ Geosciences, Technical University of Catalonia, Barcelona, Spain
}

(Received 23 August 2000; revised and accepted 29 May 2001))

\begin{abstract}
The influence of temperature on the hydraulic properties of unsaturated clays is of major concern in the design of engineered barriers in underground repositories for high-level radioactive waste disposal. This paper presents an experimental study centred on the investigation of the influence of temperature on soil hydraulic properties related to water retention and permeability. Laboratory tests were conducted on artificially prepared unsaturated fabrics obtained from a natural kaolinitic-illitic clay. Special attention is given to the testing procedures involving controlled suction and temperature oedometer cells and the application of the vapour equilibrium technique at high temperatures. Retention curves at different temperatures show that total suction tends to reduce with increasing temperatures at constant water content. Temperature influence on water permeability is more relevant at low matric suctions corresponding to bulk water preponderance (inter-aggregate zone). Below a degree of saturation of $75 \%$ no clear effect is detected. Experimental data show that temperature dependence on permeability at constant degree of saturation and constant void ratio is smaller than what could be expected from the thermal change in water viscosity. This behaviour suggests that phenomena such as porosity redistribution and thermo-chemical interactions, which alter clay fabric and pore fluid, can be relevant.
\end{abstract}

Key words: permeability, retention curve, suction, temperature, unsaturated clay

\section{Introduction}

The range of geotechnical engineering applications is becoming increasingly wider in recent years, mainly in the geoenvironmental area. The need to successfully tackle these new geoenviromnental problems requires the extension of current understanding of soil behaviour with the description of new phenomena and the incorporation of relevant stress and environmental state variables. Two of such variables, suction (as a stress state variable) and temperature (as an environmental state variable), are discussed in this paper regarding their effects on hydraulic features, namely the water retention capacity and the water permeability of an unsaturated clay.

The influence of temperature on the hydraulic properties of clays is of major concern in the design of engineered barriers in underground repositories for high-level radioactive waste disposal (Gens et al., 1998; Kanno et al., 1999). These

\footnotetext{
* Corresponding author. Campus Nord, Jordi Girona 1-3, Building D-2, 08034 Barcelona, Spain. Fax: +34-93 401725 1; E-mail: enrique.romero-morales@upc.es
} 
initially unsaturated barriers experience a transient wetting phase governed by the rate of absorption of natural water from the host geological medium and a transient temperature regime controlled by the decaying heat power input induced by the waste.

The distribution and transfer of humidity and their consequences on the mechanical behaviour of pavement-base-subgrade systems represent another example where seasonal and daily cyclic changes of temperature and suction regimes play an important role (Alonso, 1998).

There are a number of laboratory results concerning thermal effects on saturated water permeability (Towhata et al., 1993; Khemissa, 1998; Cho et al., 1999; Delage et al., 2000), but on the contrary, experimental information concerning unsaturated states is very limited and restricted to sandy and silty soils (Hopmans and Dane, 1986). In addition, results related to temperature effects on water retention curves have been usually limited to low suctions or low temperatures (Nimmo and Miller, 1986; Constantz, 1991; Wan, 1996; She and Sleep, 1998). To gain insight into these aspects of behaviour, a systematic research program has been carried out on artificially prepared clayey samples to investigate changes in hydraulic properties

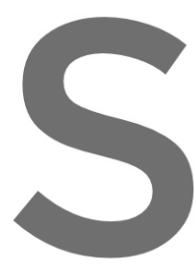

induced by heat

no appreciable

These new

consequence

the adaptation
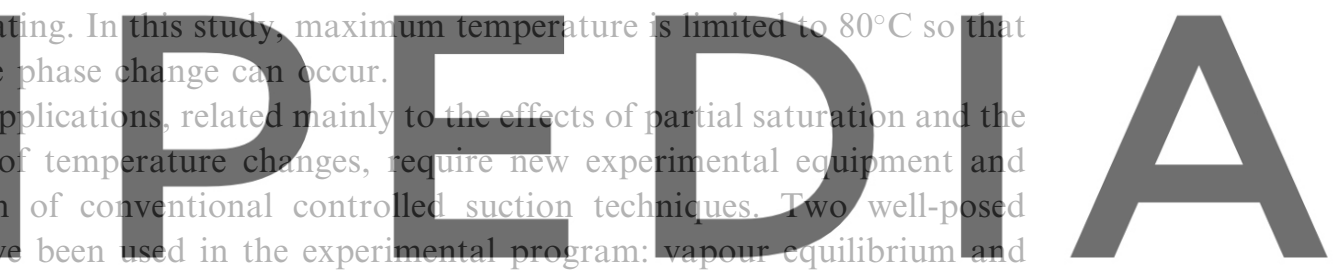

axis translation techniques. Special attention is also given in the paper to the

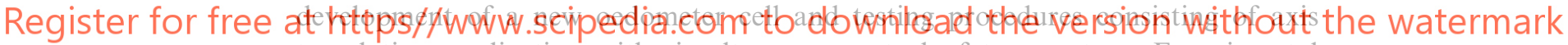
translation application with simultaneous control of temperature. Experimental aspects and problems concerning the use of the vapour equilibrium technique at high temperatures are also described.

The paper presents water retention results of gravimetric water content - temperature relationships at constant suction, and retention curves at constant void ratios under different temperatures. Water permeability and relative water permeability dependence on degree of saturation, void ratio and temperature obtained from inflow/outflow test data are also presented. Finally, a phenomenological interpretation of temperature and suction effects on hydraulic properties is described.

\section{Material, testing procedures and equipment}

\subsection{ARTIFICIALLY PREPARED MATERIAL}

Laboratory tests were conducted on an artificially prepared powder (statically compacted on the dry side of optimum water content) obtained from natural Boom clay (Mol, Belgium). This moderately swelling clay (20\%-30\% kaolinite, $20 \%-30 \%$ 
illite and $10 \%-20 \%$ smectite) has a liquid limit of $w_{L}=56 \%$, a plastic limit of $w_{P}=29 \%$, a specific gravity of $G_{s}=2.70$ and $50 \%$ of particles less than $2 \mu \mathrm{m}$.

Two types of procedures were followed to prepare samples at low and high water contents. Specimens used for the study of water retention at four different temperatures using vapour equilibrium control were prepared at low water content. In preparing these samples, powder was left in equilibrium with laboratory atmosphere at an average relative humidity of $47 \%$ (total suction $\psi \approx 100 \mathrm{MPa}$ ) to achieve a hygroscopic water content of $2.5 \pm 0.3 \%$. Soil samples $(15 \mathrm{~mm}$ in diameter and $12 \mathrm{~mm}$ high) were one-dimensionally compacted under constant water content at seven different initial dry unit weights ranging from 14.7 to $20.6 \mathrm{kN} / \mathrm{m}^{3}$.

Specimens for the study of water retention and permeability at two different temperatures using the axis translation technique were prepared at high water content. In these samples, the required quantity of demineralised water to achieve a predetermined water content of $15.0 \pm 0.3 \%$ was added to the powder, previously cured at a relative humidity of $90 \%$. After equalisation, an initial total suction of $\psi \approx 2.3 \mathrm{MPa}$ was attained at $22^{\circ} \mathrm{C}$. Afterwards, a one-dimensional and isothermal static compaction was followed at two different temperatures $\left(22\right.$ and $80^{\circ} \mathrm{C}$ ) until a

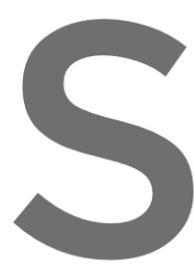

specified final

was performed in

thermostatically c

are described in

soil fabrics:

collapsible structure up
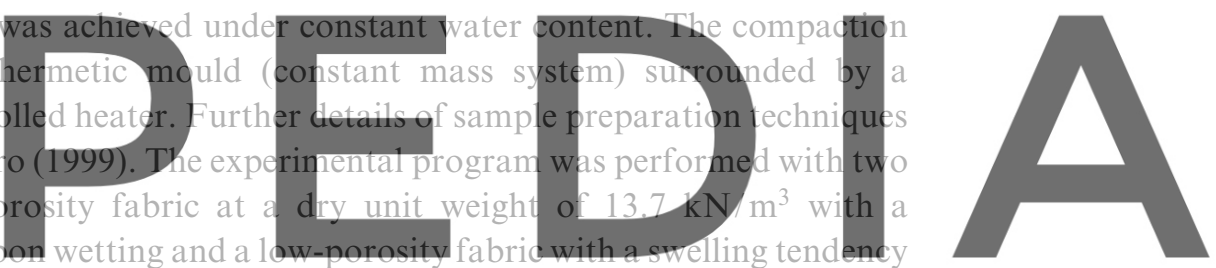

upon wetting at $16.7 \mathrm{kN} / \mathrm{m}^{3}$.

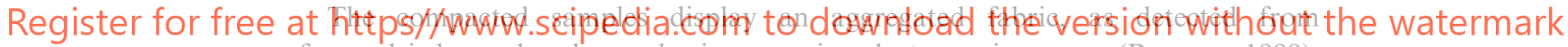
freeze-dried samples observed using scanning electron microscopy (Romero, 1999). Experimental data are interpreted on the basis of the existence of two main pore size regions, as observed from the analysis of mercury intrusion/extrusion porosimetry results (Romero et al., 1999). Firstly, an intra-aggregate porosity, containing quasi-immobile water, exists at water contents lower than $13-15 \%$ and pore sizes smaller than $150 \mathrm{~nm}$. Secondly, an inter-aggregate and interconnected porosity containing bulk water occurs at water contents greater than 13-15\%. Experimental results presented by Romero et al. (1999) show that intra-aggregate water represents $54-59 \%$ of the total volume of water in a low-porosity packing compacted at 16.7 $\mathrm{kN} / \mathrm{m}^{3}$, whereas it corresponds to a maximum of $38 \%$ for a packing compacted at $13.7 \mathrm{kN} / \mathrm{m}^{3}$.

\subsection{WATER RETENTION TESTS USING THE VAPOUR EQUILIBRIUM TECHNIQUE}

2.2.1. General aspects of the vapour equilibrium technique at different temperatures The vapour equilibrium technique is appropriate for prescribing high suction values by imposing a known total suction. This technique was used for the study of water retention at low water contents and at four different temperatures $\left(22,40,60\right.$ and $80^{\circ} \mathrm{C}$. It was 
implemented by controlling the relative humidity of a constant mass system with respect to vapour. Soil water potential was applied by means of water molecule transfer through the vapour phase from the reference system to the soil pores. This technique is associated with the control of total suction, since the gaseous phase acts like a membrane that is permeable to water but not to dissolved salts.

Partially saturated solutions with varying solute quantities were used in order to achieve the predetermined relative humidity. Sodium chloride, a non-volatile solute at the applied temperature, was chosen to prepare the aqueous solutions. Since testing was carried out at four different temperatures $\left(22,40,60,80^{\circ} \mathrm{C}\right)$ the concentrations to achieve the desired suctions had to be calculated for different temperatures. The relationship between the relative vapour pressure or activity $a_{l}$ of the $\mathrm{NaCl}$ aqueous solution and the molality of the solute $m$ (mol of $\mathrm{NaCl} / \mathrm{kg}$ of pure water), as a function of temperature $T\left({ }^{\circ} \mathrm{C}\right)$, is given by the following empirical expression (Horvath, 1985; Romero, 1999):

$$
a_{l}=1-0.035 m-m(m-3) f(T)
$$
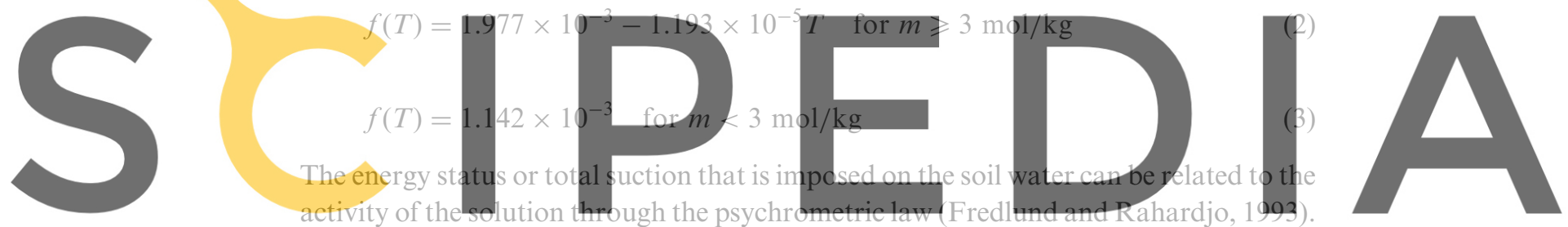

Figure 1 represents the total suction $\psi$ as a function of the molality of the $\mathrm{NaCl}$ solution

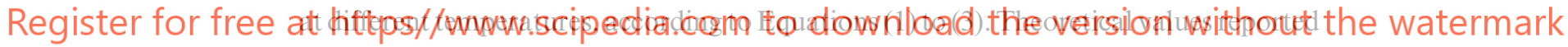

by Lang (1967) obtained from osmotic coefficients at different concentrations and temperatures of the electrolyte solution are also indicated in Figure 1. A value of $3 \mathrm{MPa}$ was selected as the total suction lower limit. This is due to the difficulty of controlling, with accuracy, high relative humidity values that require small quantities of solute. As indicated in Figure 1, the slope of the curve is steeper at low values, hindering total suction control. In addition, small variations of temperature of the order of $80.0 \pm 0.2^{\circ} \mathrm{C}$ at constant vapour pressure, can induce total suction changes of around $3.0 \pm 1.3 \mathrm{MPa}$ due to temperature effects on saturated vapour pressure and the proximity to the dew point temperature. The total suction upper limit is controlled by the salt solubility $\left(m=6.1 \mathrm{~mol} / \mathrm{kg}\right.$ at $\left.22^{\circ} \mathrm{C}\right)$ that restricts the relative humidity to a minimum of 0.75 at $22^{\circ} \mathrm{C}$.

\subsubsection{Water retention tests at low water contents}

Water retention results were obtained from isothermal wetting paths performed with the vapour equilibrium technique at four different temperatures and under free swelling conditions with zero boundary stresses. Compacted soil samples, according to the initial conditions indicated in Section 2.1, were equilibrated in hermetic jars (partially filled with $4 \times 10^{5} \mathrm{~mm}^{3}$ of $\mathrm{NaCl}$ solution) at specified temperatures (22, 


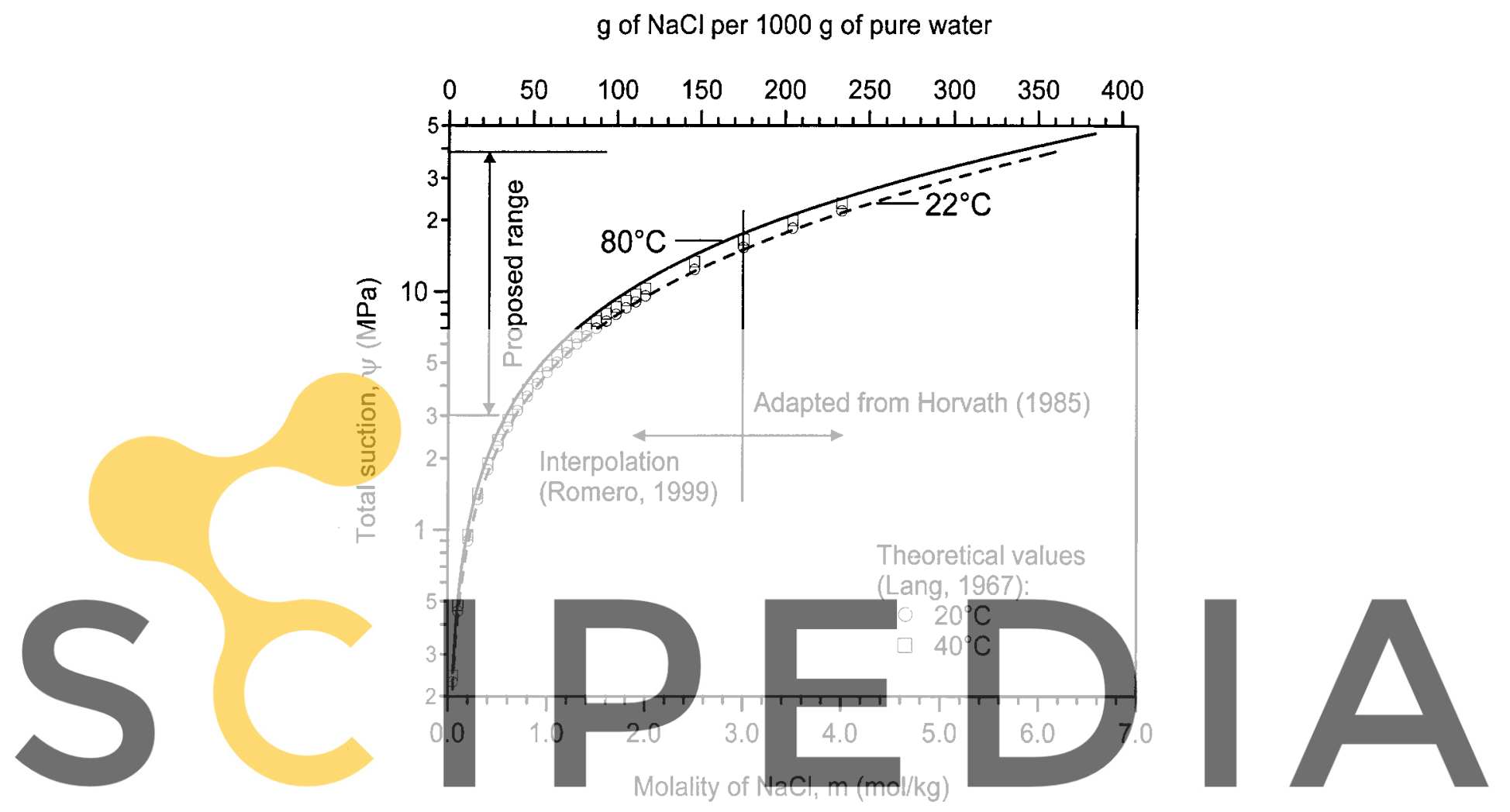

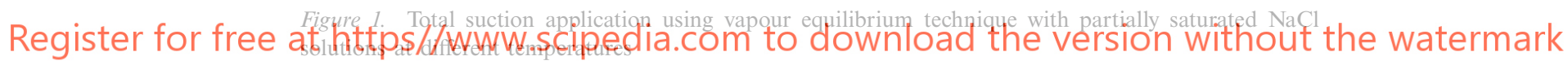

40,60 and $80^{\circ} \mathrm{C}$ ). Samples were allowed to equilibrate for a constant period of two weeks at different relative humidity values, corresponding to the following total suctions: $32,10,8,6$ and $3 \mathrm{MPa}$. At the end of each single-stage equilibrium test the different samples were carefully and quickly weighed (water content resolution of $0.02 \%$ associated with the moisture content loss during the weighing operation) and measured (volumetric resolution less than $0.2 \%$ ). In addition, the water content of the specimens was determined. More details concerning the experimental procedure are described in Romero (1999).

\subsection{WATER RETENTION AND WATER PERMEABILITY TESTS USING THE AXIS TRANSLATION TECHNIQUE}

\subsubsection{Controlled suction equipment with axis translation technique}

The axis translation technique was used for the study of water retention and permeability at high water contents and at two contrasting temperatures of 22 and $80^{\circ} \mathrm{C}$. This method is associated with the matric suction component 
$s=\left(u_{a}-u_{w}\right)$, in which soil water potential is predominantly controlled by liquid phase transfer through an interface that is permeable to dissolved salts. The procedure involves the translation of the reference air pressure by an artificial increase of the atmospheric pressure in which the soil is immersed. The air overpressure methodology was applied in the experiments with a constant air pressure of $u_{a}=0.5 \mathrm{MPa}$. The water pressure $u_{w}$ is translated into the positive range. However, a limitation of axis translation at high temperatures is that the system of air pressure regulation is open to vapour (non-constant mass), which induces soil water to evaporate.

Figure 2 shows the layout of the temperature and controlled suction system and a number of auxiliary devices necessary to perform the tests. A controlled suction oedometer cell surrounded by a thermostatically controlled heater (silicone oil bath and heater indicated by number 1 in Figure 2) was employed for the study of the soil in the low suction range $(s \leqslant 0.45 \mathrm{MPa})$. Soil temperature was measured with thermocouples located close to the sample, used as feedback signals acting on a programmable thermostat. A water volume change indicator connected to the high air-entry value (HAEV) ceramic disc (number 3 in Figure 2) and maintained at a reference laboratory temperature was used to obtain the values of inflow and
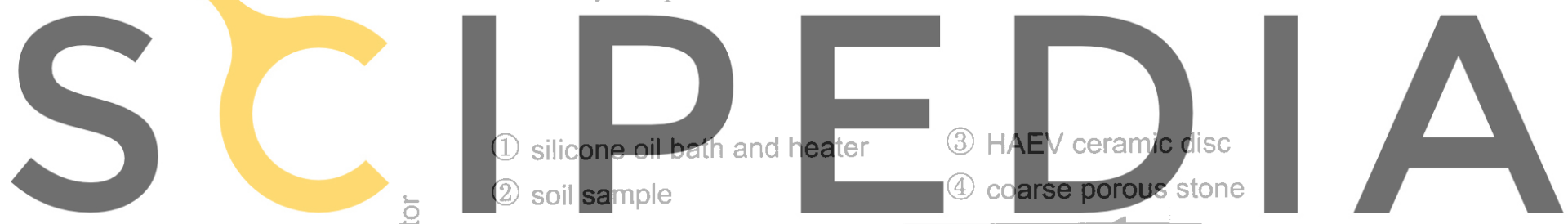

Register for free at https/ / M

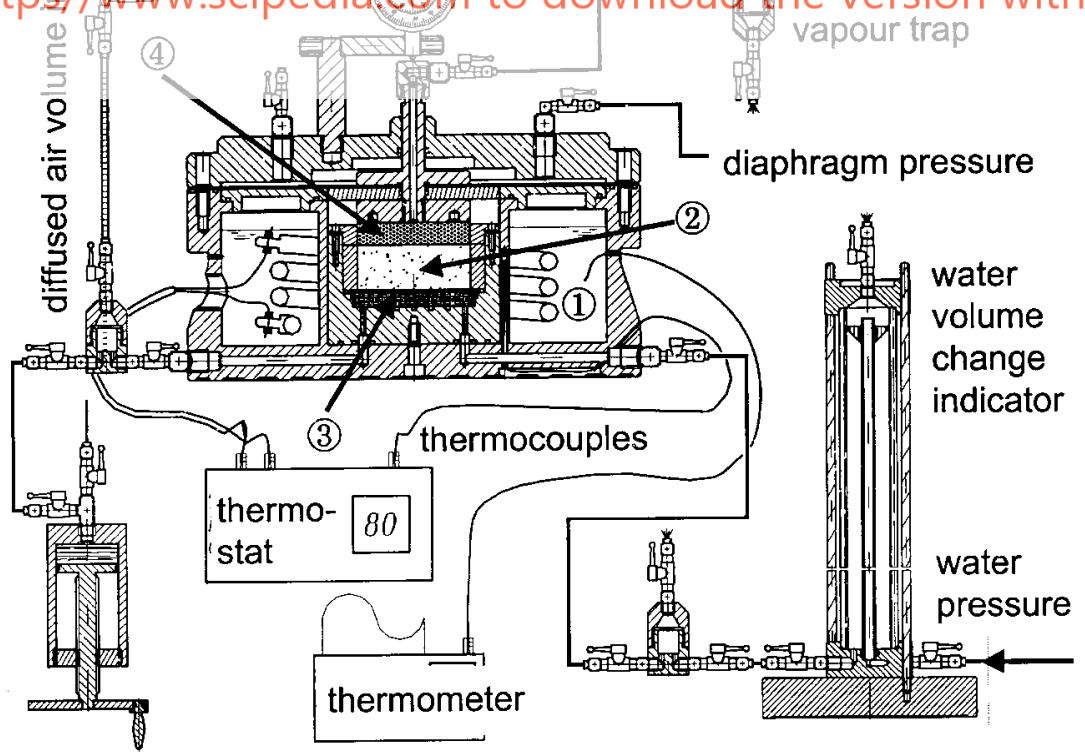

Figure 2. Experimental layout of the temperature and controlled suction system (Romero et al., 1995) 
outflow of water, as well as the water retention for each suction and temperature condition.

Once the hot sample was compacted as described in Section 2.1 and removed from the hermetic mould, it was quickly installed in the oedometer cell to minimise water content losses due to evaporation (number 2 in Figure 2). The different pieces of the oedometer cell were previously heated to the target temperature. Spurious expansions of the different elements were hence minimised while thermal equilibrium was reached. Transferring the specimen from the compaction mould to the cell induced a maximum temperature change of around $-5^{\circ} \mathrm{C}$ and water content changes between -0.6 and $-0.9 \%$. The estimated initial total suction of the heated sample is between 2.6 and 3.0 MPa. Further experimental details are described in Romero (1999).

In order to accurately determine water volume changes it is necessary to account for water volume losses due to evaporation in the air pressure system (open system to vapour). Evaporative fluxes originate due to the difference in vapour pressure between soil voids and the air pressure system (coarse porous stone, number 4 in Figure 2). Volumetric evaporative fluxes are detected in the water volume change device under steady-state conditions. Evaporative fluxes reduce with increasing

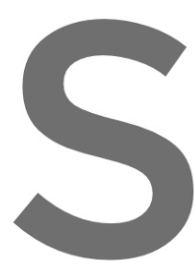

applied matric s

suctio

and with lowe

A series of $1-$

(1999) to sinuulat

fluxes are compared

different relative
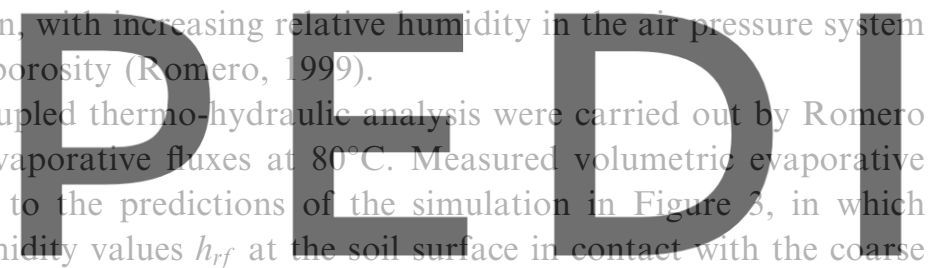

porous stone have been prescribed (95.0,98.0,99.0,99.5 and 99.9\%). A matric

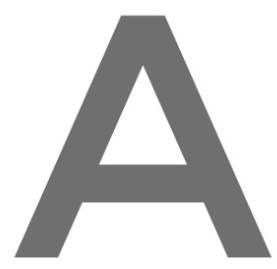

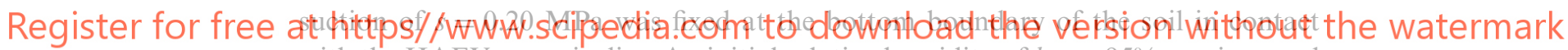
with the HAEV ceramic disc. An initial relative humidity of $h_{r o}=95 \%$ was imposed at the top boundary in contact with the coarse porous stone, which progressively tended to the different target values $h_{r f}$ previously indicated. The objective of the simulation was to determine the feasibility of matric suction equalisation throughout the sample height of $10 \mathrm{~mm}$ at $80^{\circ} \mathrm{C}$. Two different water fluxes are involved in the process. Firstly, an evaporative flux that tries to dry the clay, dependent on soil properties (mainly porosity and degree of saturation affecting vapour diffusivity) and top boundary conditions (relative humidity of the air above the evaporating surface). Secondly, a liquid water transfer through the HAEV ceramic disc that is dependent on soil and ceramic disc permeability. As observed in Figure 3, if volumetric evaporative fluxes measured at a reference temperature of $22^{\circ} \mathrm{C}$ are kept under a value of $1 \times 10^{-6}\left(\mathrm{~mm}^{3} / \mathrm{s}\right) / \mathrm{mm}^{2}$, a relative humidity higher than $98.5 \%$ is ensured in the air pressure system. This relative humidity restricts water vapour transfer at high temperatures and permits the attainment of matric suction equalisation over the entire sample height. Under these conditions, maximum matric suction at the top boundary is expected to increase up to 0.22 $\mathrm{MPa}$, as indicated in Figure 3. Therefore, a vapour trap was installed in the air pressure system to maintain a relative humidity higher than $98.5 \%$ (Figure 2 ). 


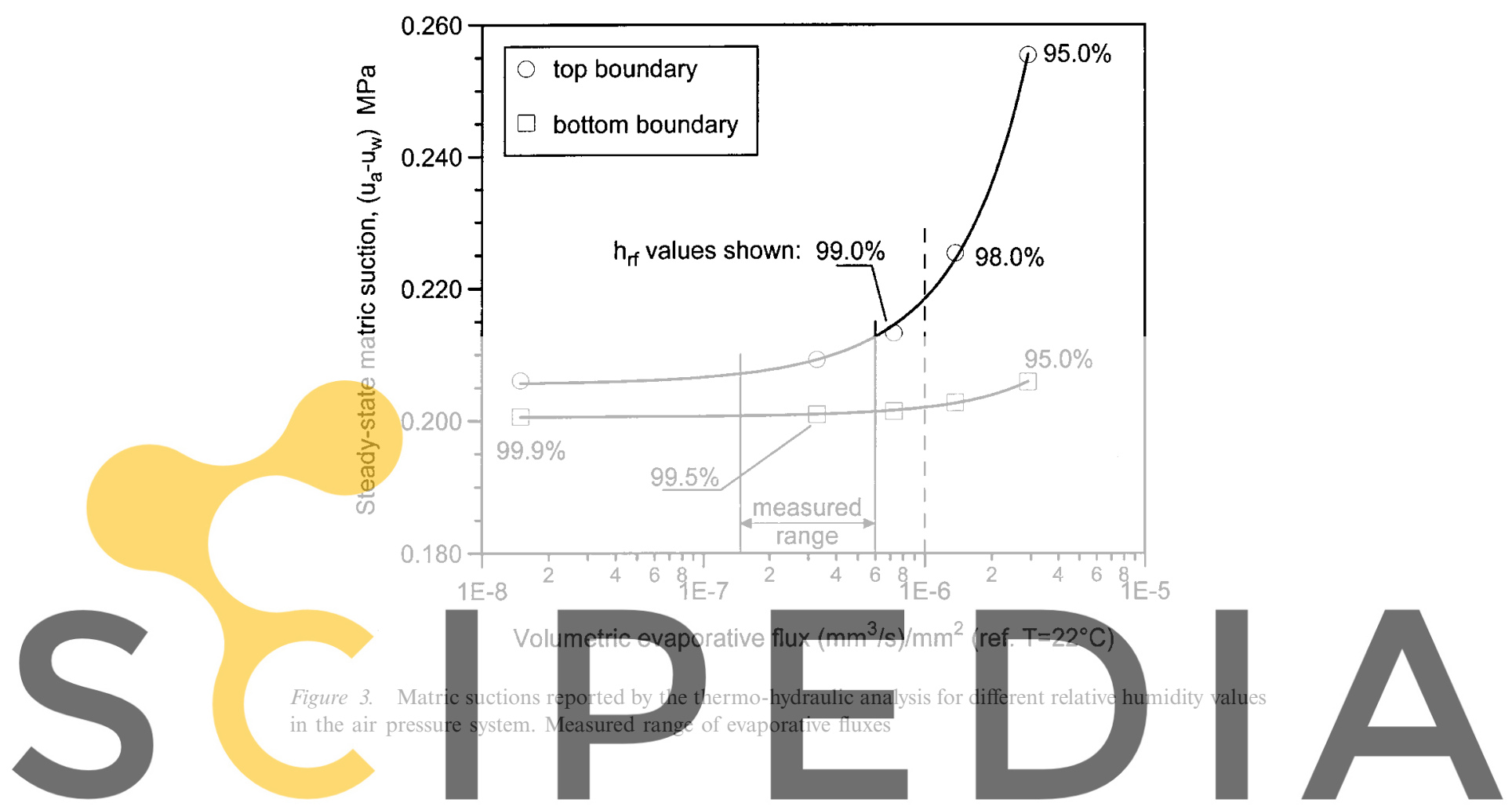

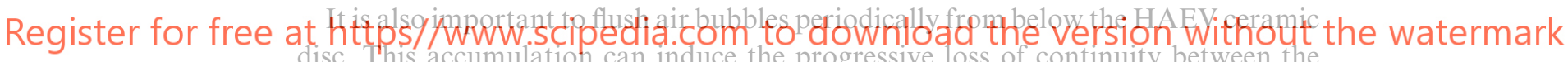

pore water and the water in the measuring system, especially at high temperatures and high-applied matric suctions. An increase of the air diffusion coefficient through HAEV ceramic discs at high temperatures has been measured by Romero (1999): between $6 \times 10^{-11}$ and $1 \times 10^{-10} \mathrm{~m}^{2} / \mathrm{s}$ at $22^{\circ} \mathrm{C}$ and between $2 \times 10^{-10}$ and $3 \times 10^{-10} \mathrm{~m}^{2} / \mathrm{s}$ at $80^{\circ} \mathrm{C}$. A diffused air volume indicator was therefore incorporated in the water pressure system to allow periodic flushings and measurements, as observed in Figure 2.

\subsubsection{Water retention and water permeability tests at high water contents}

Isothermal wetting and drying cycles were performed on both compacted fabrics at constant net vertical stresses (varying between $26 \mathrm{kPa}$ and $1.2 \mathrm{MPa}$ ) or constant volume (isochoric) conditions. In this way, a wide void ratio range - from 0.60 to 0.95 - was covered. The same matric suction steps were followed in the wetting and drying paths: $0.45,0.20,0.06$ and $0.01 \mathrm{MPa}$. Water permeability was determined under transient conditions by analysing the inflow data (wetting paths) or outflow data (drying paths). On the other hand, water retention values were measured only in wetting paths after matric suction equalisation under isochoric conditions. 
The water permeability values were obtained from inflow and outflow data using the expressions that are presented below and the correction proposed by Kunze and Kirham (1962), which takes into account ceramic disc impedance. The inflow/outflow approach is an unsteady-state method based on the use of the pressure plate apparatus and initially developed by Gardner (1956) only for outflow. A step matric suction decrease/increase was applied to the soil and the transient inflow/outflow of water was carefully measured with time and interpreted with a simplified resolution of Richards's equation. Experimental methods for determining water permeability are described in Vicol (1990), Fredlund and Rahardjo (1993) and Jucá and Frydman (1996). The volume $Q(t)$ of intruded/ extracted water at time $t$ is given by the following expression (Kunze and Kirham, 1962):

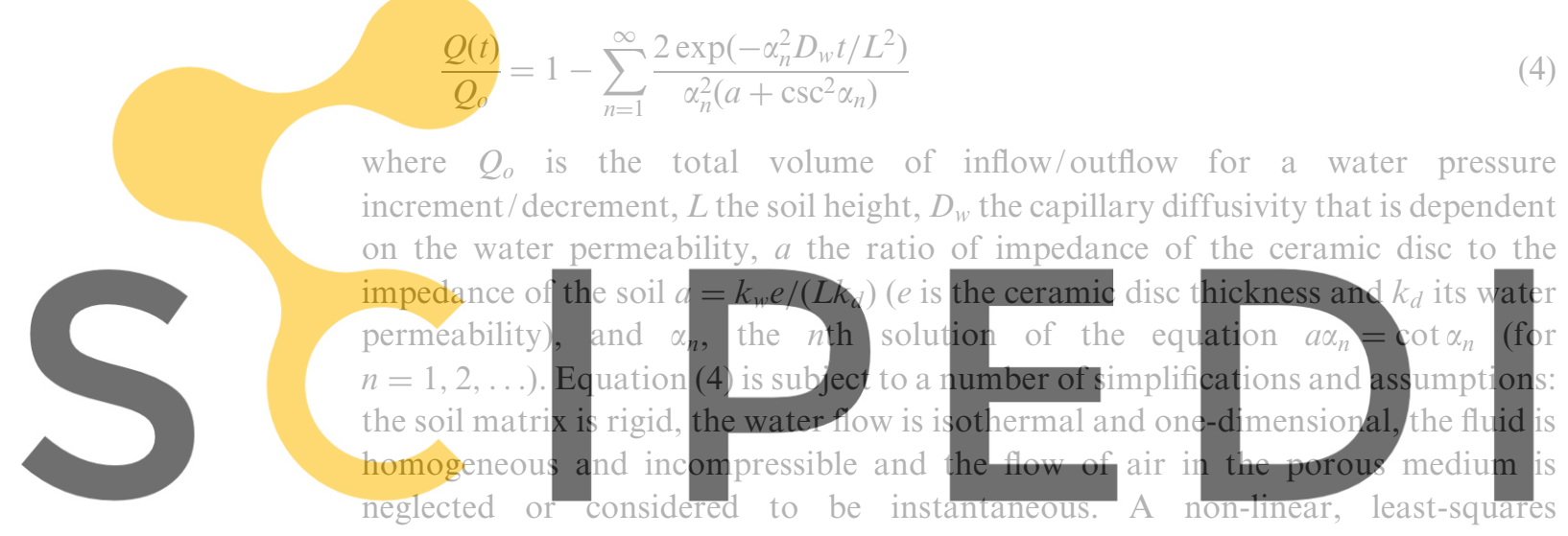

optimisation procedure was used according to Equation (4) to approximate test

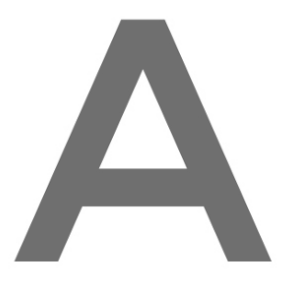

the model, in order to obtain the $D_{w}$ parameter. Test data were evaluated using inflow/outflow results that did not exceed $30 \%$ of the total change $\left(0.20 \leqslant Q(t) / Q_{o} \leqslant 0.30\right)$. Under this short period, $D_{w}$ and the soil volume are not constant, but their variation can be neglected as a first approximation. Water permeability $k_{w}$ was calculated from the following expression:

$$
k_{w}=\frac{D_{w} \gamma_{w} Q_{o}}{V \delta u_{w}}
$$

where $\delta u_{w}$ is the water pressure increment/decrement, $V$ the volume of the sample and $\gamma_{w}$ the water unit weight.

\section{Test results and interpretations}

\subsection{WATER RETENTION RESULTS}

\subsubsection{Water retention results at low water contents}

Figure 4 summarises the water retention data obtained through the application of the vapour equilibrium technique. Temperature derivatives at constant total suction 
$(\partial w / \partial T)_{\psi}$ are also indicated. It can be seen that moisture retention capacity of the clay at low water contents (corresponding to the adsorbed water contained in the intra-aggregate porosity) is influenced by temperature. At a given total suction, water content reduces with increasing temperatures, as clearly detected for 8,10 and $32 \mathrm{MPa}$. However, the reduction at $\psi=6 \mathrm{MPa}$ is hardly noticeable. In addition, it appears that temperature derivatives $(\partial w / \partial T)_{\psi}$ tend to increase at higher total suctions, showing less evident temperature effects. Water retention data reported by Romero (1999) of the same soil and ranging from $\psi=55$ to $240 \mathrm{MPa}$ showed no noticeable temperature effects.

Lower values of moisture retention under constant total suction and higher temperatures are in agreement with experimental results reported by Wan (1996) testing Boom clay up to $50^{\circ} \mathrm{C}$ and using vapour equilibrium technique. In addition, lower water contents for the same matric suction and higher temperatures are also consistent with data reported in the low suction range (sandy and silty material) by Saha and Tripathi (1979), by Nimmo and Miller (1986), by Hopmans and Dane (1986), by Constantz (1991) and by She and Sleep (1998),

Total suction - temperature plots at constant water content varying between $6 \%$
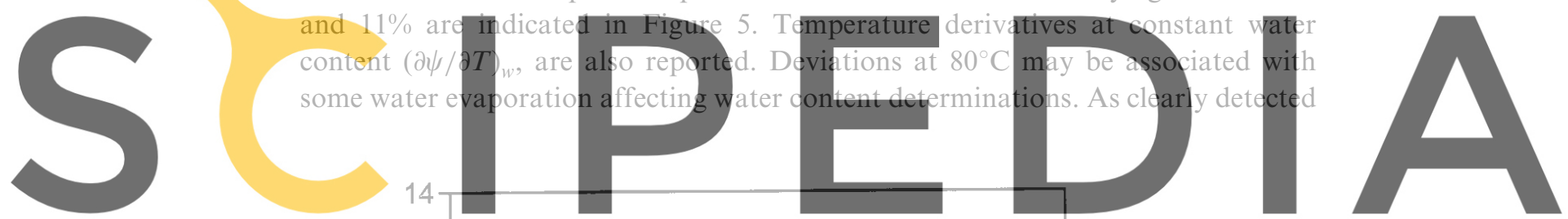

Register for free at https//wWw.SW

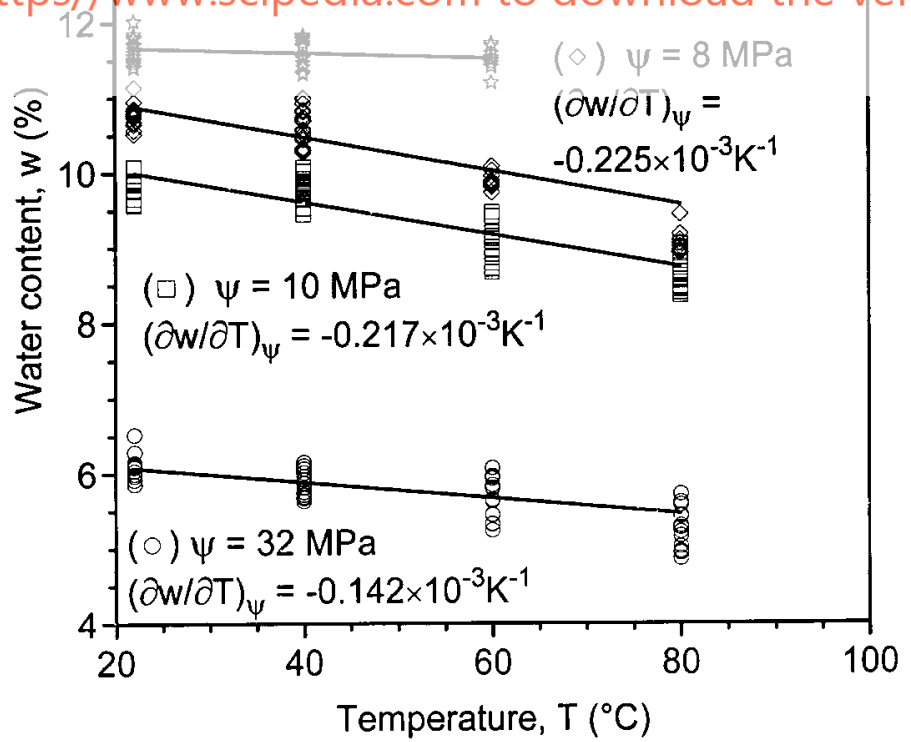

Figure 4. Water content - temperature plots at constant total suction 


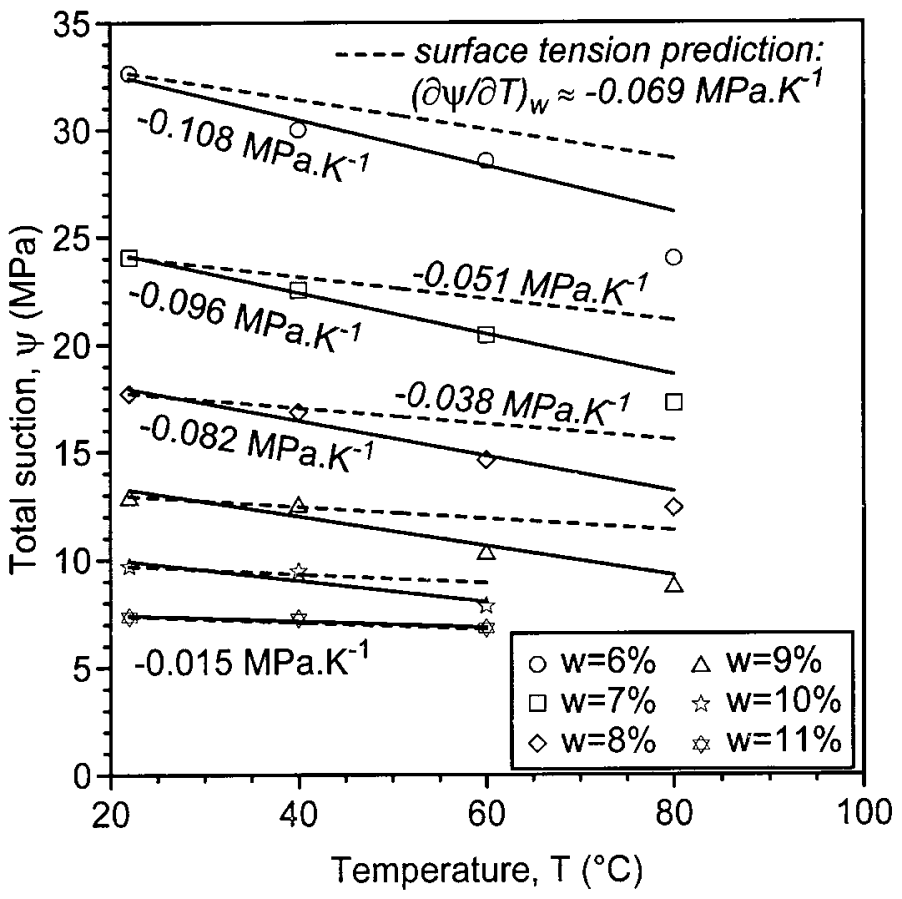

Figure 5. Total suction - temperature plots at constant water content

in the figure, for a specified water content contained in the intra-aggregate porosity, total suction tends to decrease with increasing temperatures.

Following the suggestion of Philip and de Vries (1957), numerous experimental results of temperature effects on matric suction $s$ at constant water content $w$ and for monotonic paths have been interpreted on the basis of temperature dependence on surface tension of water $\sigma(T)$ :

$$
\left(\frac{\partial s(w, T)}{\partial T}\right)_{w}=\frac{s(w, T)}{\sigma(T)} \frac{\mathrm{d} \sigma(T)}{\mathrm{d} T}=\frac{b}{a+b T} s(w, T)
$$

The simplest empirical relationship between $\sigma$ and $T$ is a linear fit as indicated in Equation (6), which describes temperature effects in the experimental range: $\sigma(T)=a+b T$, with $a=0.118 \mathrm{Nm}^{-1}$ and $b=-1.54 \times 10^{-4} \mathrm{Nm}^{-1} \mathrm{~K}^{-1}$. A theory to allow the incorporation of temperature induced changes in wetting coefficients in Equation (6) has been proposed by Grant and Salehzadeh (1996) derived from thermodynamics of interfacial phenomena. Integrating Equation (6) between a reference temperature $T_{r}$ and an observational temperature $T$, temperature effects 
on energy status of soil water can be derived from the following coefficients affecting a reference matric suction $s\left(w, T_{r}\right)$ (Grant and Salehzadeh, 1996):

$$
\frac{s(w, T)}{s\left(w, T_{r}\right)}=\left(\frac{a_{1}+b_{1} T}{a_{1}+b_{1} T_{r}}\right)^{b_{1}}
$$

where $a_{1}$ and $b_{1}$ are empirical coefficients reflecting the actual behaviour compared to the surface tension mechanism. If values estimated from the analysis of experimental data tend to $b_{1}=1$ and $a_{1}=a / b=-766 \mathrm{~K}$, then temperature induced changes may be described by temperature effects on surface tension.

Comparisons between total suction - temperature plots at constant water content and predicted in terms of surface tension mechanism of pure water are also shown in Figure 5. At higher temperatures, the theory under-predicts the influence of temperature on total suction. Therefore, the capillary model cannot solely explain the effect of temperature at high suctions, as expected for adsorbed water in relatively active clays. Additional thermal disturbances altering clay fabric and intra-aggregate fluid chemistry are to be postulated. Test results showing greater temperature dependence have been reported by Hopmans and Dane (1986), Nimmo and Miller (1986) and Constantz (1991) in the low suction range for sandy and silty soils.

\subsubsection{Overall picture of water retention results: low and high water contents}

The overall picture of water retention results is depicted in Figure 6, in which the relationship between suction and water content under isochoric conditions and two different temperatures $\left(22\right.$ and $\left.80^{\circ} \mathrm{C}\right)$ is plotted. Data at high total suctions ( $3 \mathrm{MPa} \leqslant \psi \leqslant 32 \mathrm{MPa}$ ), corresponding to the intra-aggregate water, were interpolated at constant dry unit weight from free swelling data, following the procedure detailed in Section 2.2.2. Wetting data at low matric suctions $(s \leqslant 0.45 \mathrm{MPa})$ were obtained from isochoric tests, according to the procedure indicated in Section 2.3.1. The end point of the wetting curves at $80^{\circ} \mathrm{C}$ is somewhat lower in terms of water content compared to the end point of the wetting curves at ambient temperature. This fact is due to the lower gravimetric water storage capacity at higher temperatures, mainly caused by water dilatation and possibly due to thermal expansion of entrapped air.

Test results shown in Figure 6 have been fitted to a modified form of the van Genuchten (1980) expression for water content $w$ as a function of matric suction $s$ at the observational temperature $T$ (Romero, 1999):

$$
\frac{w}{w_{s a t}}=S_{r}=C(s)\left[\frac{1}{1+\left(\alpha_{T} s\right)^{n}}\right]^{m} ; \quad C(s)=1-\frac{\ln \left[1+\frac{s}{a_{r}}\right]}{\ln \left[1+\frac{a}{a_{r}}\right]} \quad \text { with } 0.1 a<a_{r} \leqslant a
$$




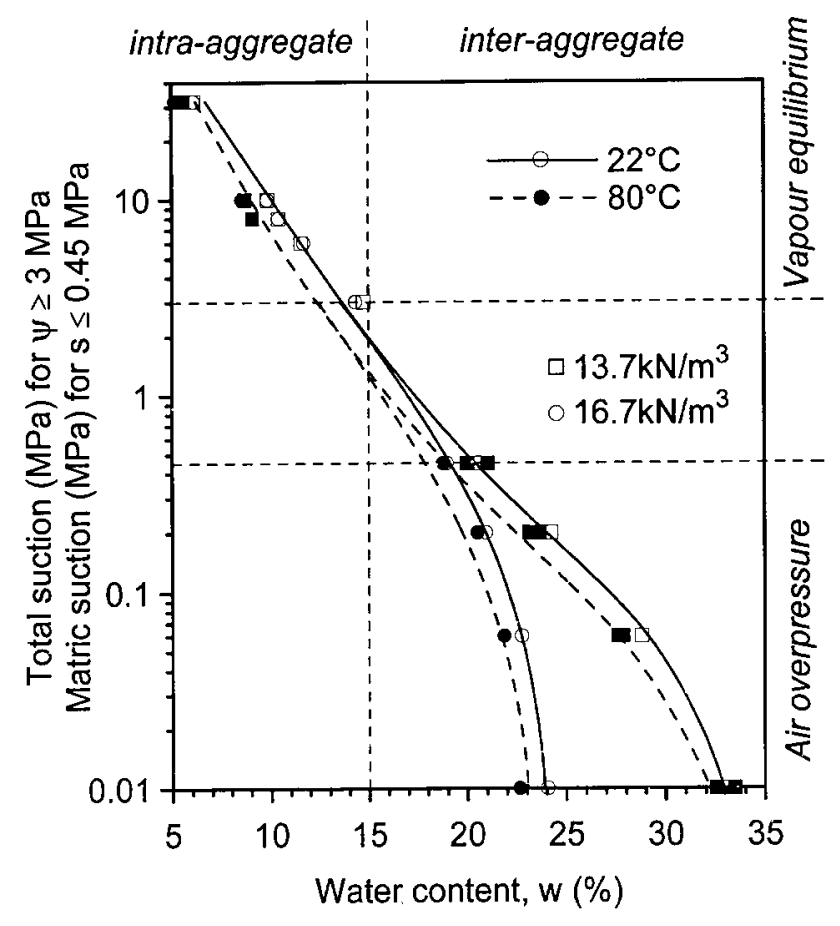

Figure 6. Water retention curves for different temperatures at fixed dry unit weights

$$
\alpha_{T}=\alpha_{r}\left(\frac{a_{1}+b_{1} T_{r}}{a_{1}+b_{1} T}\right)^{b_{1}}
$$

Parameters $n$ and $m$ are the same as used in van Genuchten's (1980) expression. The parameter $\alpha_{T}$ in Equation (8) is like van Genuchten's $\alpha$, and is mainly associated (inversely) with the air-entry value of the soil. However, $\alpha_{T}$ allows for a temperature effect as it is associated with the observational temperature $T . \alpha_{T}$ is related to $\alpha_{r}$ (the value determined at the reference temperature $T_{r}$ (the ambient temperature)) through Equation (9).

Equation (8), like van Genuchten's expression, is not adequate to fit retention curve data for high activity clayey soils. For this reason, the equation is modified using an expression that is similar to the proposal of Fredlund and Xing (1994). The objective of this correction is to make the curve tend to a linear relationship between the logarithm of suction and water content in the high suction zone (the intra-aggregate zone). However, the physical meaning of the parameters involved in this correction are different from the proposal of Fredlund and Xing (1994). Material parameter $a$ represents the intersection with the y-axis of this linear part 
of the semi-log plot. This parameter depends mainly on the specific surface (or alternatively on the liquid limit) of the clay, as suggested by Romero and Vaunat (2000). On the other hand, $a_{r}$, is a fitting parameter that controls the shape and slope of the retention curve in the high suction zone (some low-activity soils and artificially aggregated double-porosity fabrics deviate from a linear relationship). In clays it is realistic to assume $a=a_{r}$, so that the correction function is $C(s)=1-\ln (1+s / a) / \ln (2)$.

For simplicity in the curve-fitting process, it was assumed that temperature effects only affect the $\alpha_{T}$ parameter and the water storage capacity $w_{s a t}$. Parameters $C(s), n$ and $m$ are considered temperature independent.

A non-linear curve-fitting algorithm using least-squares method was used to determine parameters $n, m, \alpha_{r}$ and $\alpha_{T}$ for the two soil fabrics and temperatures. A number of assumptions were made to simplify the fitting procedure. Total suctions $\psi$ above $3 \mathrm{MPa}$ were considered equivalent to matric suctions $s$, assuming that the osmotic suction $\pi$ does not substantially alter the values: $\psi=s+\pi$. It should be noted that an osmotic component of $\pi \approx 0.4 \mathrm{MPa}$ at $22^{\circ} \mathrm{C}$ was measured by Romero (1999) using the squeezing technique. Therefore, this assumption is reasonable. For simplicity, $a=a_{r}=300 \mathrm{MPa}$, according to test results reported by the same author. In addition, as it is expected that $b_{1} \rightarrow 1$, it is accurate enough to consider $b_{1}=1$ in Equation (9). It can be seen in Figure 6 that water storage capacity at the reference temperature $T_{r}=295 \mathrm{~K}\left(22^{\circ} \mathrm{C}\right)$ is $w_{\text {sat }}=32.9 \%$ for the low-density fabric and $w_{\text {sat }}=23.9 \%$ for the high-density packing. At $T=353 \mathrm{~K}\left(80^{\circ} \mathrm{C}\right), w_{\text {sat }}=32.2 \%$ for the low-density fabric and $w_{\text {sat }}=23.1 \%$ for the high-density packing.

Fitting parameters were found to be $n=1.14, m=0.20$ and $\alpha_{r}=21.3 \pm 0.8$ $\mathrm{MPa}^{-1}$ for the low-density packing, and $n=0.75, m=0.35$ and $\alpha_{r}=1.55 \pm 0.43$ $\mathrm{MPa}^{-1}$ for the high-density fabric. Fitted values of $\alpha_{T}$ were $25.0 \pm 0.7 \mathrm{MPa}^{-1}$ for the low-density packing and $1.98 \pm 0.75 \mathrm{MPa}^{-1}$ for the high-density fabric. The value of $a_{1}$ was $-608 \pm 89 \mathrm{~K}$, which was somewhat higher than the surface-tension prediction. Therefore, the temperature parameter $\alpha_{T}$ should be considered as an empirical fitting parameter. It is clear that the surface tension model cannot explain the temperature dependence.

In spite of the assumptions involved in the fitting process, it can be seen that Equations (8) and (9) are adequate to fit water retention data at different temperatures over a wide suction range (Figure 6). It is suggested that two regions can be defined in the retention curves shown in Figure 6, an intra-aggregate porosity region and an inter-aggregate region, the latter with a water content high enough to partially fill the inter-aggregation voids. The inter-aggregate region presents a dominant capillary storage mechanism containing bulk water, dependent on void ratio. In this region, temperature induced changes can be mainly associated with temperature dependence on interfacial tension and wetting coefficient, thermal expansion of entrapped air, dissolved air release upon heating or interfacial tension change caused by dilatation of water (Hopmans and Dane, 1986; Nimmo and Miller, 1986; Mohamed et al., 1992; Grant and Salehzadeh, 1996; Wan, 1996; She and Sleep, 
1998). At low water contents, moisture is contained in the intra-aggregate porosity, and the influence of equilibrated dry unit weights is found to be negligible. The suction - water content relationship is therefore mainly dependent on clay microstructure and pore fluid chemistry. The intra-aggregate domain, which presents an adsorption storage mechanism and contains quasi-immobile water, will be water-saturated in a wetting path before water fills the macropores. Inside the aggregates, predominant temperature effects are expected to be induced by thermo-chemical disturbances altering clay fabric and quasi-immobile water, as well as temperature influence on chemical induced water adsorption potential (Zhang et al., 1993; Almanza et al., 1995). However, little theoretical development of such mechanisms has been accomplished because of the difficulty in contrasting experimental data on active clays under a wide range of suctions and temperatures.

\subsection{WATER PERMEABILITY RESULTS}

3.2.1. Temperature effects on water permeability. Interpretation of results

Measured water permeability values are represented in Figure 7 for different degrees of saturation, void ratios and at two different temperatures (the upper plot represents data at $22^{\circ} \mathrm{C}$ and the lower graph shows data at $80^{\circ} \mathrm{C}$ ). Data have been fitted with curves representing two different void ratios: 0.60 and 0.93 . An important dependence of water permeability on void ratio and degree of saturation is observed. The effect of temperature, though not so remarkable, appears to be more significant at higher degrees of saturation.

In Figure 8, water permeability values have been grouped into different degree of saturation ranges and plotted versus void ratios for both temperatures (the upper plot represents data at $22^{\circ} \mathrm{C}$ and the lower graph shows data at $80^{\circ} \mathrm{C}$ ). Temperature effect is more important under near-saturated conditions with a preponderance of bulk water, as indicated in the lower graph which has the data for $22^{\circ} \mathrm{C}$ superimposed as dotted lines. The ratio of $k_{w}\left(80^{\circ} \mathrm{C}\right) / k_{w}\left(22^{\circ} \mathrm{C}\right) \approx 1.3$ for comparable void ratio and water contents. On the other hand, below a degree of saturation of $75 \%$, corresponding to the upper limit of the intra-aggregate porosity, no clear difference in $k_{w}$ is detected. The ratio $k_{w}\left(80^{\circ} \mathrm{C}\right) / k_{w}\left(22^{\circ} \mathrm{C}\right) \approx 1.0$.

At $S_{r} \approx 75 \pm 5 \%$, the coefficient of permeability presents a variation of one order of magnitude when changing the void ratio from $e=0.90$ to 0.60 . This variation is just as important as the change of the degree of saturation from $S_{r}=72 \%$ to $50 \%$ for a fixed $e=0.93$, according to Figure 7 .

Temperature effects on water permeability at saturation are usually derived from viscosity changes under free water considerations. This interpretation can be extrapolated to unsaturated states at constant void ratio $e$ and water content $w$, according to the following expression:

$$
\left.\frac{k_{w}(e, w, T)}{k_{w}\left(e, w, T_{r}\right)}\right|_{e, w}=\frac{\rho_{w}(T) \mu_{w}\left(T_{r}\right)}{\rho_{w}\left(T_{r}\right) \mu_{w}(T)} \approx 1+\beta_{T}\left(T-T_{r}\right)
$$




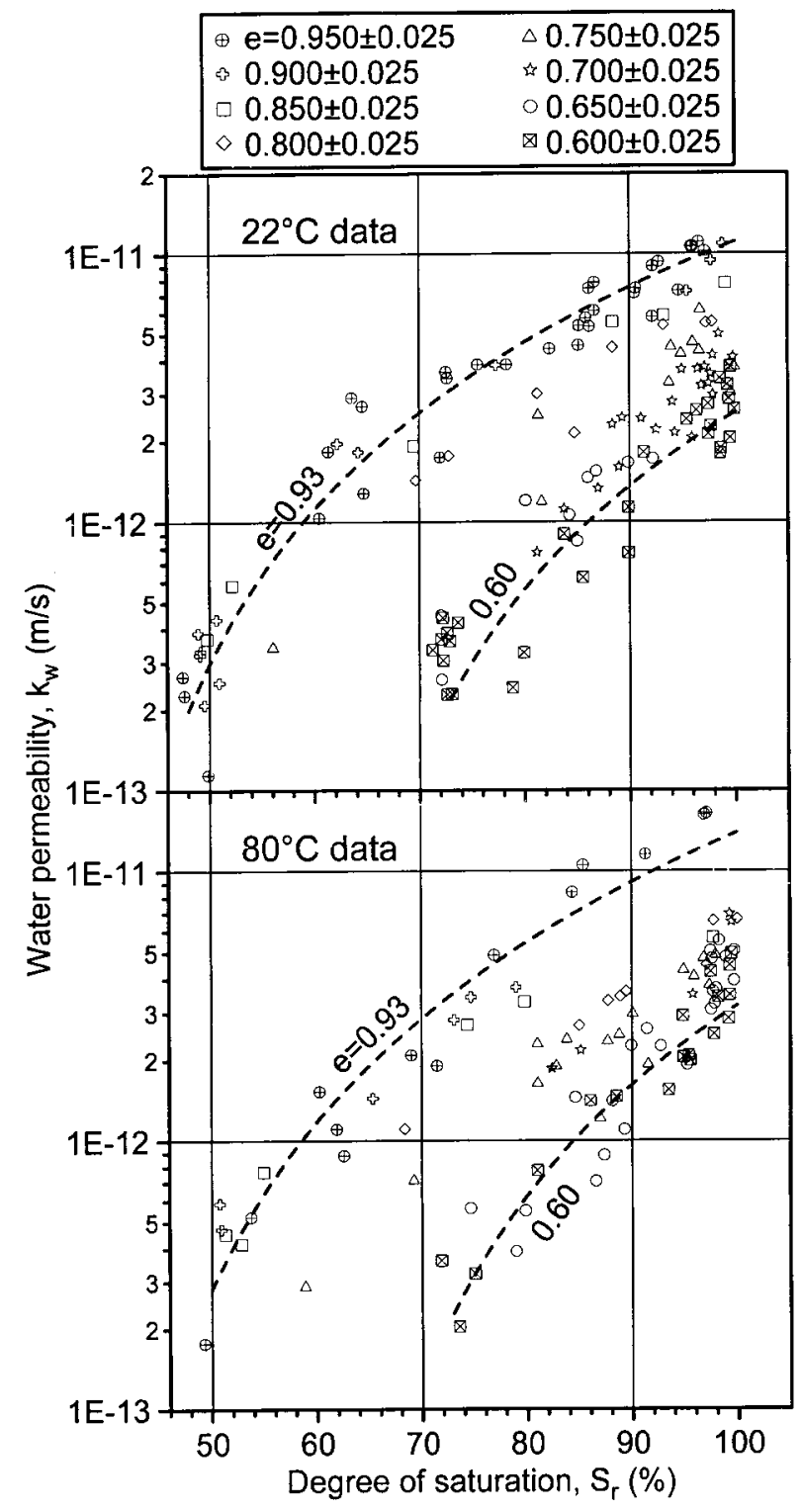

Figure 7. Water permeability vs. degree of saturation at $22^{\circ} \mathrm{C}$ (upper graph) and $80^{\circ} \mathrm{C}$ (lower graph)

where $\rho_{w}$, is the density of water, $\mu_{w}$, the absolute viscosity and $\beta_{T}=0.030 \mathrm{~K}^{-1}$ (for a reference temperature $T_{r}=22^{\circ} \mathrm{C}$ ) an empirical coefficient that fits relative viscosity data over a temperature range of $22^{\circ} \mathrm{C} \leqslant T \leqslant 80^{\circ} \mathrm{C}$. The slight increase of permeability with temperature at $S_{r}=95 \pm 5 \%$ of $k_{w}\left(80^{\circ} \mathrm{C}\right) / k_{w}\left(22^{\circ} \mathrm{C}\right)=1.3$ cannot be explained in terms of a reduction of free water viscosity in the same interval of temperature (solid lines at $80^{\circ} \mathrm{C}$ and dashed lines at $22^{\circ} \mathrm{C}$ in the lower graph of 


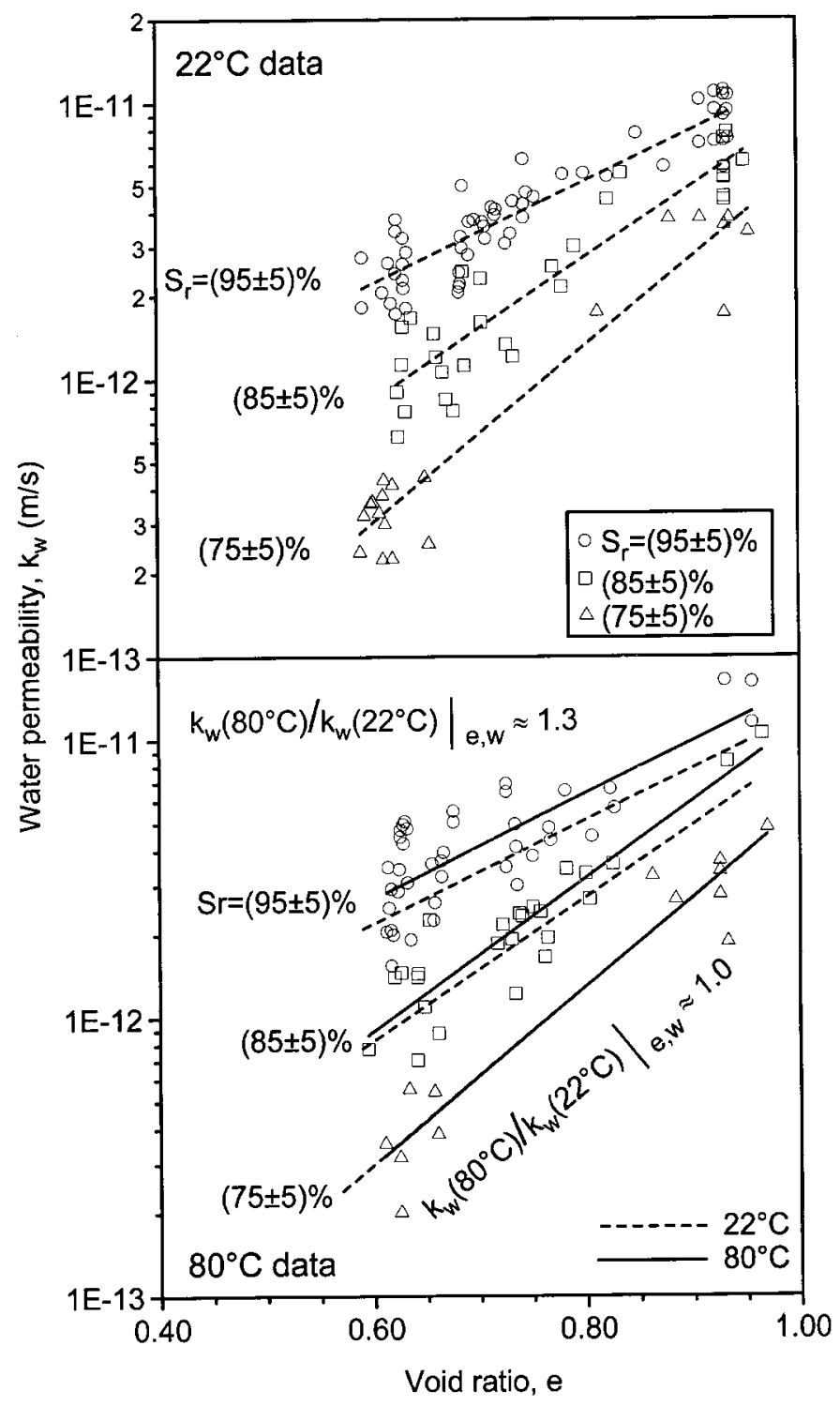

Figure 8. Water permeability vs. void ratio for constant degrees of saturation at $22^{\circ} \mathrm{C}$ (upper graph) and $80^{\circ} \mathrm{C}$ (lower graph). Data at $22^{\circ} \mathrm{C}$ is also superimposed on the lower graph as dotted lines

Figure 8). Experimental data are associated with $\beta_{T}=0.005 \mathrm{~K}^{-1}$ at nearly saturated conditions $S_{r}=95 \pm 5 \%$. At lower bulk water contents, in the proximity of the intra-aggregate zone at $S_{r}=75 \pm 5 \%$, experimental results show $\beta_{T} \rightarrow 0$.

As far as saturated states are concerned, Towhata et al. (1993) studied the effects of temperature on a kaolinite-clay up to $90^{\circ} \mathrm{C}$ using indirect methods. An additional temperature effect, over that predicted on the basis of free water considerations, was 
observed (an estimated value of $\beta_{T}=0.042 \mathrm{~K}^{-1}$ was obtained from experimental data). Permeability measurements up to $120^{\circ} \mathrm{C}$ have also been reported on a saturated montmorillonite by VoIckaert et al. (1996). A value of $\beta_{T}=0.014$ $\mathrm{K}^{-1}$ can be deduced from experimental data analysed up to $120^{\circ} \mathrm{C}$. Khemissa (1998) reported direct measurements of permeability for a saturated kaolinite-clay up to $130^{\circ} \mathrm{C}$. An estimated $\beta_{T}=0.010 \mathrm{~K}^{-1}$ was obtained from experimental data up to $80^{\circ} \mathrm{C}$. Recently, Cho et al. (1999) studied water permeability changes of saturated bentonites over a temperature range of 20 to $80^{\circ} \mathrm{C}$. A slightly higher value of around $\beta_{T}=0.022 \mathrm{~K}^{-1}$ was obtained.

The scarce experimental data available about temperature effects on water permeability in unsaturated soils have always been limited to low suctions and temperatures. Experimental results have been reported by Haridasan and Jensen (1972) on a silty soil up to $35^{\circ} \mathrm{C}$ using the pressure plate outflow method. Somewhat greater temperature dependence seems to have been observed at higher volumetric water contents (although this fact has not been stressed by the authors). Hopmans and Dane (1986) tested a sandy soil using tensiometers up to $45^{\circ} \mathrm{C}$. Lower values of permeability at high temperatures than those predicted from viscosity changes can be interpreted, at constant porosity, if the amount of bulk water and the cross-sectional area, available for water to flow, decreases. This effect is associated with aggregate expansion upon heating, which gives rise to smaller inter-aggregate voids affecting bulk water flow. Apart from porosity redistribution, thermo-chemical interactions on soil fabric and pore fluid properties could also be relevant. Flocculation/dispersion phenomena have been observed when temperature increases in clays (Almanza et al., 1995). In addition, it seems possible that the sensitivity of viscosity to temperature is different for intra-aggregate and bulk water.

\subsubsection{Relative water permeability}

Relative water permeability values $k_{w} / k_{w s}$ (unsaturated water permeability to permeability at saturation) are shown in Figure 9 as a function of the effective saturation ratio $S_{e}$ and for different constant void ratios $e$ and temperatures $T$, following the expression:

$$
\left.\frac{k_{w}(e, w, T)}{k_{w s}(e, T)}\right|_{e, T}=S_{e}^{\lambda} ; \quad S_{e}=\frac{w-w_{r e f}}{\frac{e}{G_{s}}-w_{r e f}}=\frac{S_{r}-\frac{G_{s} \cdot w_{r e f}}{e}}{1-\frac{G_{s} \cdot w_{r e f}}{e}}
$$

where $\lambda$ is an empirical constant usually related to pore size distribution. $S_{e}$ can be evaluated on the basis of water content $w$ or degree of saturation $S_{r}$. Subscript ref refers to a reference water content. In order to avoid a high dependence of $\lambda$ on void ratio, Romero et al. (1999) normalised $S_{e}$ with respect to the water contained inside the intra-aggregate porosity. Below a threshold water content of $w_{\text {ref }}=13 \%$, the relative water permeability is maintained $k_{w} / k_{w s}<0.01$ (Romero, 1999). This 


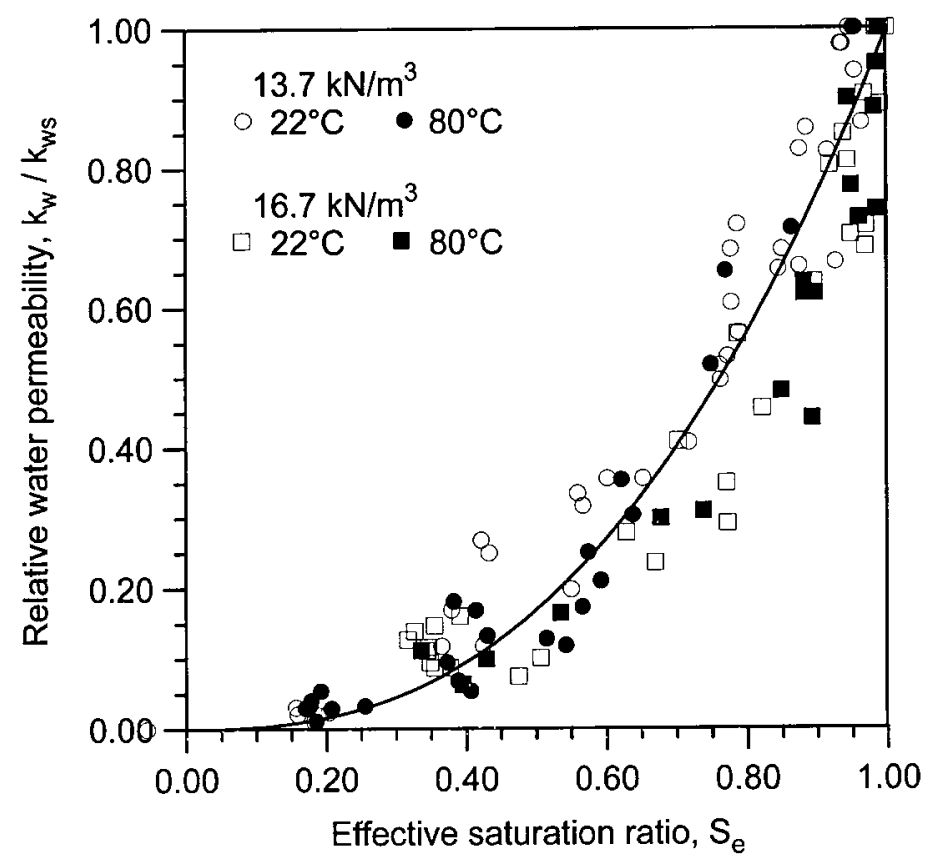

Figure 9. Relative water permeability values vs. effective saturation ratios for different void ratios and temperatures (Romero et al., 1999)

quasi-immobile water content is consistent with the intra-aggregate water content determined from retention curves presented in Figure 6.

Relative permeability values have been fitted to Equation (11). A parameter $\lambda=2.6$ adequately fits experimental data corresponding to the different void ratios and temperatures. As observed in Figure 9, no important temperature dependence has been detected for the relative permeability function.

\section{Conclusions}

As a summary of the experimental technique and equipment used, the tests performed and the results obtained, the following conclusions may be drawn. Vapour equilibrium using partially saturated $\mathrm{NaCl}$ solutions and axis translation techniques have demonstrated their applicability for studying the combined effects of temperature and partial saturation. However, a careful control with auxiliary devices (vapour traps and diffused air volume indicators) is required to use axis translation technique at high temperatures. Important problems concerning this technique refer to the accumulation of diffused air under the HAEV ceramic disc and uncontrolled evaporative fluxes, which affect the measurement of transient and steady-state inflow and outflow of water. 
Experimental results, which are presented for different artificially prepared unsaturated clay fabrics, offer a consistent pattern of temperature effects on water retention and water permeability over a wide range of suction and temperature. In the studied range of the intra-aggregate porosity zone, water retention of the clay is influenced by temperature. Total suction tends to reduce with increasing temperatures at constant water content. However, the influence that temperature has over water retention cannot only be attributed to temperature dependence on surface tension. Additional thermal disturbances altering clay fabric and intra-aggregate fluid chemistry are possible. Wetting retention curves, covering a wide suction range (from 0.01 to $32 \mathrm{MPa}$ ), have been presented for different void ratios and temperatures. The results indicate a clear delimiting zone separating a region of intra-aggregate porosity from an inter-aggregate adjoining area. In both regions, different temperature induced phenomena affecting water retention are expected.

Temperature influence on water permeability is more relevant at low suctions corresponding to bulk water preponderance (inter-aggregate zone). Below a degree of saturation of $75 \%$ (in the proximity of the intra-aggregate zone) no clear effect is detected. Experimental data show that temperature dependence at constant degree of saturation and void ratio is smaller than what could be expected from the thermal change in water viscosity. Thermo-chemical effects altering clay fabric (flocculation or dispersion), porosity redistribution (creating preferential pathways or blocking macropores) and pore fluid chemistry (affecting viscosity) could be relevant. Relative water permeability values at constant void ratio showed no temperature dependence.

Finally, on the basis of phenomenological evidence, expressions and material parameters for retention curves and water permeability functions at different temperatures have been presented.

\section{Acknowledgements}

The first author acknowledges the financial support provided by TDOC grant from the Comissionat per a Universitats i Recerca de la Generalitat de Catalunya. The support of DGICYT through research grant PB95-0771 is also acknowledged. The first author thanks Dr. A. Di Marianno for her help during the preparation of the paper. The comments made by the reviewers of the paper were greatly appreciated.

\section{References}

Almanza, R., Castañeda, R. and Silva, G. (1995) Temperature-electrolyte effects on clay soil liners, in Proceedings of the 1st International Conference on Unsaturated Soils. Vol. 1 Paris, 1995 (edited by E. E. Alonso and P. Delage). Balkema/Presses des Ponts et Chaussées. pp. 343-348. 
Alonso, E. E. (1998) Succión y humedad en bases y explanadas de carreteras, in Proceedings of the Simposio Internacional sobre Drenaje Interno de Firmes y Explanadas. Granada, November 1998. pp. 3-55.

Cho,W. J., Lee, J. O. and Chun, K. S. (1999) The temperature effects on hydraulic conductivity of compacted bentonite, Applied Clay Science, 14, 47-58.

Constantz, J. (1991) Comparison of isothermal and isobaric water retention paths in nonswelling porous materials, Water Resour. Res. 12(12), 3165-3170.

Delage, P, Sultan, N. and Cui, Y. J. (2000) On the thermal consolidation of Boom clay, Can. Geotech. J., 37, 343-354.

Fredlund, D. G. and Rahardjo, H. (1993) Soil mechanics for unsaturated soils, John Wiley and Sons, Inc. New York.

Fredlund, D. G. and Xing, A. (1994) Equations for the soil-water characteristic curve, Can. Geotech. J., 31, 521-532.

Gardner, W. R. (1956) Calculation of capillary conductivity from pressure plate outflow data, Soil Sci. Soc. Am. Proc., 20, 317-320.

Gens, A., García-Molina, A. J., Olivella, S., Alonso, E. E. and Huertas, F. (1998) Analysis of a full scale in situ test simulating repository conditions, Int. J. Numer. Anal. Meth. Geomech., 22, 515-548.

Grant, S. and Salehzadeh, A. (1996) Calculation of temperature effects on wetting coefficients of porous solids and their capillary pressure functions, Water Resour. Res., 32(2), 261-270.

Haridasan, M. and Jensen, R. D. (1972) Effect of temperature on pressure head - water content relationship and conductivity of two soils, Soil Sci. Soc. Am. Proc., 36, 703-708.

Hopmans, J. W and Dane, J. H. (1986) Temperature dependence of soil hydraulic properties, Soil Sci. Soc. Am. J., 50, 4-9.

Horvath, A. L. (1985) Handbook of aqueous electrolyte solutions: physical properties, estimation and correlation methods, Ellis Horwood Limit, New York.

Jucá, J. F. T. and Frydman, S. (1996) Experimental techniques. State of the art report, in Proceedings of the 1st International Conference on Unsaturated Soils. Vol. 3 Paris, 1995 (edited by E. E. Alonso and P. Delage). Balkema/Presses des Ponts et Chaussées. pp. 1257-1292.

Kanno, T., Fujita, T., Takeuchi, S., Ishikawa, H., Hara, K. and Nakano, M. (1999). Coupled thermo-hydro-mechanical modelling of bentonite buffer material, Int. J. Numer. Anal. Meth. Geomech., 23, 1281-1307.

Khemissa, M. (1998) Mesure de la perméabilité des argiles sous contrainte et température, Rev. Franç. Géotech., 82, 11-22.

Kunze, R. J. and Kirkham, D. (1962) Simplified accounting for membrane impedance in capillary conductivity determinations, Soil Sci. Soc. Am. Proc., 26, 421-426.

Lang, A. R. G. (1967) Osmotic coefficients and water potentials of sodium chloride solutions from $0^{\circ} \mathrm{C}$ to $40^{\circ} \mathrm{C}$, Australian J. Chem., 20, 2017-2023.

Mohamed, A. M., Yong, R. N. and Cheung, S. C. H. (1992) Temperature dependence of soil water potential, Geot. Testing J., 15(4), 330-339.

Nimmo, J. R. and Miller, E. E. (1986) The temperature dependence of isothermal moisture vs. potential characteristics of soils, Soil Sci. Soc. Am. J., 50, 1105-1113.

Philip, J. R. and de Vries, D. A (1957) Moisture movement in porous materials under temperature gradients, Trans. American Geophysical Union, 38(2), 222-232.

Romero, E., Lloret, A. and Gens, A. (1995) Development of a new suction and temperature controlled oedometer cell, in Proceedings of the 1st International Conference on Unsaturated Soils. Vol. 2 Paris, 1995 (edited by E. E. Alonso and P. Delage). Balkema/Presses des Ponts et Chaussées. pp. 553-559. 
Romero, E. (1999) Characterisation and thermo-hydro-mechanical behaviour of unsaturated Boom clay: an experimental study. PhD Thesis, Universidad Politécnica de Cataluña.

Romero, E. and Vaunat, J. (2000) Retention curves of deformable clays, in Experimental Evidence and Theoretical Approaches in Unsaturated Soils (eds. A. Tarantino and C. Mancuso) Rotterdam: Balkema, pp. 91-106.

Romero, E., Gens, A. and Lloret, A. (1999) Water permeability, water retention and microstructure of unsaturated Boom clay, Engineering Geology, 54, 117-127.

Saha, R. S. and Tripathi, R. P. (1979) Effect of temperature on the soil water content suction relationship, J. Indian Soc. Soil Sci., 27, 222-224.

She, H. Y. and Sleep, B. E. (1998) The effect of temperature on capillary pressure-saturation relationships for air-water and perchloroethylene-water systems, Water Resour. Res., 34(10), 2587-2597.

Towhata, I., Kuntiwattanakul, P., Seko, I. and Ohishi, K. (1993) Volume change of clays induced by heating as observed in consolidation tests, Soils and Foundations, 33(4), $170-183$.

van Genuchten, M.Th. (1980) A closed-form equation for predicting the hydraulic conductivity of unsaturated soils, Soil Sci. Soc. Am. J., 44, 892-898.

Vicol, T. (1990) Comportement hydraulique et mécanique d'un sol fin non saturé. Application à la modélisation. PhD Thesis, Ecole Nationale des Ponts et Chaussées, Paris.

Volckaert, G., Bernier, F., Alonso, E. E., Gens, A., Samper, J., Villar, M. V., Martin-Martin, P. L., Cuevas, J., Campos, R., Thomas, H., Imbert, C. and Zingarelli, V. (1996) Thermal-hydraulic-mechanical and geochemical behaviour of the clay barrier in radioactive waste repositories (model development and validation). Publications of the European Communities, EUR 16744 EN, Luxembourg.

Wan, A. W. L. (1996) The use of thermocouple psychrometers to measure in situ suctions and water contents in compacted clays. PhD Thesis, University of Manitoba.

Zhang, F., Zhang, Z. Z., Low, P. F. and Roth, C. B. (1993) The effect of temperature on the swelling of montmorillonite, Clay Minerals, 28, 25-31. 